\title{
The Shielding Effect of the built in Damper Cage in a Synchronous Machine
}

\author{
J. Bacher ${ }^{1}$, G. Maier ${ }^{1}$ \\ ${ }^{1}$ Institute of Electrical Machines and Drive Technology \\ E.M.A, University of Technology Graz \\ Kopernikusgasse, 8010 Graz (Austria) \\ phone:+43 316 8738601, fax: +43 316 8737244, e-mail: Bacher@ema.tugraz.at, Maier@ema.tugraz.at
}

\begin{abstract}
Because of the cost efficiency of modern machines, the design of a damper winding in a synchronous machine must be met the following both subjects. One criterion is a functional design, and a second one is an as cheap as possible design.

Normally, the complete damper cage is substituted by the slot wedges of the rotor. But this replacement cage isn't as effective as the original cage [1]. Furthermore the damping moments of the eddy currents in the massive rotor and in massive parts of a synchronous machine don't changed. So in the case of an absent damper winding the sum of the damping moments decreases.

In order to answer the question of the aims of a built in complete damper cage it must be differentiated between synchronous generators and motors. Generators have to produce sinusoidal voltages. As a result, the damping of higher harmonics in the generator is important. Furthermore, the damping of the negative sequence caused by an increased asymmetric load must be defined by the consumer. Normally, a five percent asymmetric load is acceptable.

In the case of synchronous motors the damping of load impulses are important. One result is the difference between the damping moment of a complete built in damper cage and an incomplete built in damper cage. In addition this paper treats about the damping of higher harmonics and the damping of the negative sequence rotating field.
\end{abstract}

\section{Key words}

Complete and incomplete damper cage, massive rotor, shielding effects, higher harmonics.

\section{Introduction}

Often modern machine design is characterised by low costs. This is also true in the case of a turbo generator. Turbo generators in the power range within two hundred megawatts have only in special cases, such as an increased asymmetric load, an additional built in damper cage. But this one must be extra specified by the consumer. Normally a five percent asymmetric load is acceptable. In this case the built in damper cage is replaced by a damper cage built up of electric conductive slot wedges.

The shielding factor of a damper cage is defined in [2] and [3]. But it must be decided between a complete built in damper cage and a built in damper cage with gaps between the poles. Both cage types are symmetrical. But in the case of different air gaps between the damper bars or in the case of an asymmetric damper cage caused by a broken damper bar the calculation of the shielding factor is to complex. So, in both cases the shielding factor respectively the damping factor is measured at a test machine. So in this paper a measurement method is presented by which the ratio between the shielding effect of a complete damper cage and a damper cage with broken bars can be determined.

In order to characterise the shielding effect of a winding the harmonic orders which are possible in a synchronous machine must be found. For this, all windings in the machine must be checked. So, it can be found which harmonic orders must be dominant and which orders can be appeared.

Besides the effects of an absent damper winding are discussed. First, the shielding effect of a complete built in damper cage with respect to the field winding is analysed. The field winding current of both design variants are compared to each other.

Second, the transient behaviour of a synchronous machine is checked. The damping effect of the synchronous machine is important in connection with the dynamic behaviour. Thus the effectiveness of the damper circuits must be characterised by the damping coefficient $C_{D}$. This damping coefficient depends very strongly on the machine characteristics [1].

\section{Higher Harmonics}

Based on an only sinusoidal three phase power supply all the windings of a classical synchronous machine are checked. This means that the produced harmonic orders in a machine are assigned to the machine windings. 


\section{A. Stator winding}

Usually, the stator winding of a synchronous machine is a symmetrical three phase winding. The stator winding is star- or delta-connected. Normally, only the mains frequency is considered. So the magneto motive force (MMF) produced by the stator winding is described by (1):

$$
\begin{aligned}
F_{m m f(x, t)}= & F_{m m f_{1}} \cdot \sin \left(\omega \cdot t-\Theta_{s}\right)+ \\
& +F_{m m f_{5}} \cdot \sin \left(\omega \cdot t+5 \cdot \Theta_{s}\right)+ \\
& +F_{m m f_{7}} \cdot \sin \left(\omega \cdot t-7 \cdot \Theta_{s}\right)+ \\
& +F_{m m f_{11}} \cdot \sin \left(\omega \cdot t+11 \cdot \Theta_{s}\right)+\ldots
\end{aligned}
$$

The waves of the orders $+7,+13,+19$ etc. move in the direction of the fundamental rotating field and the waves of the orders $-5,-11,-17$ etc. move into the opposite direction. All orders of the multiple of three must be disappeared, because of the symmetrical three-phasestator-winding.

The variation of the self inductance along the circumference of the stator winding of a salient pole synchronous machine is a periodic function and it can be characterised by (2):

$$
L_{s}=L_{s 0}+L_{s 2} \cdot \cos \left(2 \cdot \Theta_{r}\right)
$$

The rotor angle must be transformed to the stator coordinate system. This transformation is given in (3):

$$
\Theta_{s}=\Theta_{r}+(1-s) \cdot \omega \cdot t
$$

During the normal play of a synchronous machine the slip $\mathrm{s}=0$. As a result, the fundamental MMF produces harmonic orders of $-1,+1$ and +3 . The second harmonic order MMF produces harmonic orders of $+5,+7$ and +3 etc. During all other behaviours of a synchronous machine, such as load impulses, short circuits, counter-current braking or starting the slip $s$ is vary between +1 and -1 . Therefore all harmonic orders which can appear in the stator current because of the variation of the self inductance along the circumference of the stator winding vary similar with the slip s.

\section{B. Rotor winding}

The rotor of a synchronous machine has two windings. On the one hand there is the field winding and on the other hand there is the damper winding. A salient-pole synchronous machine has a concentrated-field-winding and a turbo generator has a distributed-field-winding. In the first case the sinusoidal MMF will be got by a sineshaped pole and in the second case the sinusoidal MMF is given by a distributed field winding. As a result, only two of three rotor slots are wrapped.

The field winding of a synchronous machine is supplied by DC (Direct Current). The higher harmonics of the distributed field winding are given by the Fourier analyse of the trapezoid shaped MMF. The MMF of the field winding is given in (4).

$$
\begin{aligned}
F_{m m f(x, t)}= & F_{m m f_{1}} \cdot \sin \Theta_{r}+ \\
& +F_{m m f_{3}} \cdot \sin 3 \cdot \Theta_{r}+ \\
& +F_{m m f_{5}} \cdot \sin 5 \cdot \Theta_{r}+ \\
& +F_{m m f_{7}} \cdot \sin 7 \cdot \Theta_{r}+\ldots
\end{aligned}
$$

The rotor is moved in the direction of the main rotating field of the stator. The field winding is uniaxial. As a result a rotating field must be compensated by two rotating fields because the field winding can only produces an alternating field. One field rotates into the positive direction and the other one field rotates into the negative direction.

\section{Damper Cage}

The damper winding in a synchronous machine is different made. A salient pole machine has often no damper bars in the pole gaps and a turbo generator has normally a complete built in damper cage. The damping of the higher harmonics by the damper winding depends on its leakage coefficient (5).

$$
\sigma_{d}=\pi^{2} \cdot v^{2} \cdot \frac{\tau_{S t a b}}{\tau_{p}} \cdot \frac{\delta}{\tau_{p}} \cdot \lambda_{N}
$$

The damping effect of the damper winding is better when the leakage coefficient is smaller. It is best when the leakage coefficient is zero. This means that an interference field is damped to zero by the damper winding. From (5) can be derived two facts. First, small frequencies are damped better than higher frequencies. Second, the leakage coefficient depends very strong on the ratio of the slot pitch to the pole pitch. Smaller bar pitches lead to smaller leakage coefficients.

The ratio between the fictive field amplitude and the real field amplitude is given by the damping factor of a complete damper cage in (6).

$$
k_{D}=\frac{B_{v}}{B_{v}^{\prime}}=\frac{\sigma_{D}}{1+\sigma_{D}}
$$

\section{Slot ripples}

Finally, the higher harmonic orders caused by the slot ripples of the stator and the rotor slots are determined in this subsection. The air gap permeance variations due to the stator and rotor slotting may be written as in (7), [4]:

$$
\begin{aligned}
\lambda\left(\theta_{S}, t\right) & =\sum_{i=0}^{\infty} \lambda_{i, S} \cdot \cos \left(i \cdot \frac{N_{S}}{p} \cdot \theta_{S}\right) . \\
& \cdot \sum_{j=0}^{\infty} \lambda_{j, R} \cdot \cos \left[j \cdot \frac{N_{R}}{p} \cdot \theta_{S} \cdot(1-s) \cdot \omega \cdot t\right]
\end{aligned}
$$


The stator slot number is marked by $i$ and the rotor slot number is market by $\mathrm{j}$. First, when $\mathrm{j}=0$ and $\mathrm{i}=0$ and (7) is multiplied by the fundamental MMF of the machine the largest flux density is given by (8).

$$
\widehat{B}_{0}=\mu_{0} \cdot \lambda_{0, R} \cdot \lambda_{0, S} \cdot F_{m m f_{1}}
$$

Besides the fundamental flux density the first combination of slots is interest because its flux density is considerable too. This combination appears twice. First, when $\mathrm{j}$ $=0$ and $\mathrm{i}=1$ the air gap permeance variation is given by (9).

$$
\lambda\left(\theta_{S}, t\right)=\lambda_{0, S} \cdot \lambda_{1, S} \cdot \cos \left(\frac{N_{S}}{p} \cdot \theta_{S}\right)
$$

The fundamental flux density is already subtracted in (9). In the case of the four pole test machine the stator slot $\mathrm{N}_{\mathrm{S}}$ $=36$ and the pole pairs are 2 . The results of flux densities are given in (10).

$$
\begin{aligned}
& B_{17}=\widehat{B}_{17} \cdot \sin \left(\omega \cdot t+17 \cdot \theta_{S}\right) \\
& B_{19}=\widehat{B}_{19} \cdot \sin \left(\omega \cdot t-19 \cdot \theta_{S}\right)
\end{aligned}
$$

In the case when only the rotor has slots and the stator is without slots $(i=0, j=1)$ the following equation can be derived from (7)

$$
\begin{aligned}
\lambda\left(\theta_{S}, t\right) & =\lambda_{0, S} \cdot \lambda_{1, R} . \\
& \cdot \cos \left[\frac{N_{R}}{p} \cdot \theta_{S} \cdot(1-s) \cdot \omega \cdot t\right]
\end{aligned}
$$

The number of rotor slots $\mathrm{N}_{\mathrm{R}}=24$. The calculated flux densities are presented in (12):

$$
\begin{aligned}
& B_{11}=\widehat{B}_{11} \cdot \sin \left(\omega \cdot t+11 \cdot \theta_{S}\right) \\
& B_{13}=\widehat{B}_{13} \cdot \sin \left(\omega \cdot t-13 \cdot \theta_{S}\right)
\end{aligned}
$$

The results in (10) and (12) are valid during the normal behaviour of a synchronous machine when the slip is zero. The frequencies are integers. During all other behaviours the flux densities have terms of slip frequency too.

The well-known equation (13) returns the same harmonic orders for the stator and rotor slotting.

$$
\begin{array}{ll}
\text { Stator } & v_{N, 1}=i \cdot \frac{N_{1}}{p} \pm 1 \\
\text { Rotor } & v_{N, 2}=i \cdot \frac{N_{2}}{p} \pm 1
\end{array}
$$

The harmonic orders of the stator slotting are related to the stator and the rotor harmonic orders are related to the rotor.

\section{E. Saturation}

If the main flux path are saturated then the air gap flux density will be distorted. This mean that the air gap flux density wave differs remarkable from a sinusoidal wave. In [4] is given that not only the forward rotating fundamental flux density wave produces saturation harmonics but also the backward rotating wave. The flux density for the fundamental flux is given in (14).

$$
B_{n, s a t}=\widehat{B}_{n, s a t} \cdot \cos \left(n \cdot \omega \cdot t-n \cdot \theta_{S}\right)
$$

And the saturation harmonics of the backward rotating wave are given in (15).

$$
B_{n, s a t}=\widehat{B}_{n, s a t} \cdot \cos \left(n \cdot \omega \cdot t+n \cdot \theta_{S}\right)
$$

Noteworthy is that the factor $\mathrm{n}$ appears in the space-depending term $n \cdot \theta_{S}$ as well as in the time-depending term $n \cdot \omega \cdot t$.

\section{Measurements and results}

Measurements at the test machine, the measurement equipment and the necessary theory are explained here. To this end this chapter is classified into the following subsections.

\section{A. Measurement at a machine with and without a com- plete damper cage.}

As stated at the beginning the modern machine design is often without a built in damper winding. For this reason the difference of a machine with and without a complete built in damper cage in reference to the shielding factor must be determined by a qualified measurement. So the test machine is special adapted by a damper cage with skewed damper bars. In order to determine the higher harmonics induced into the field winding the field winding current is Fourier analysed.

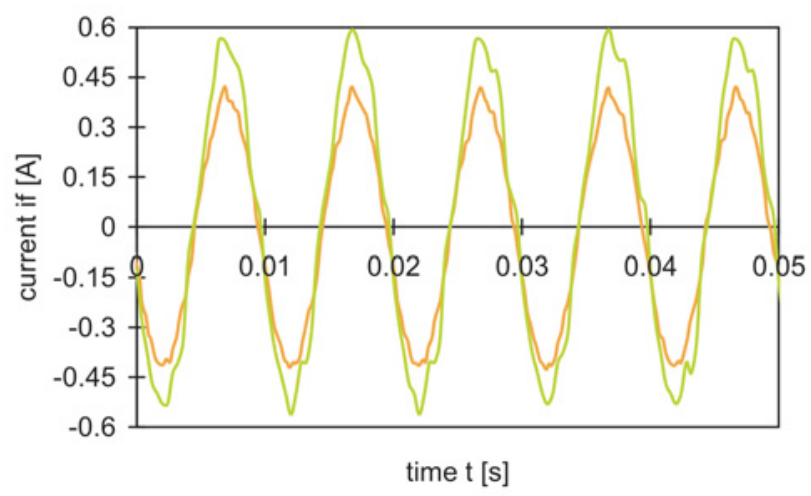

Fig. 1. The field winding current of the test machine

The test machine is asymmetric loaded. By it the damper cage works. When the shielding factor of the damper cage is perfect the superimposed alternating current to the 
direct current of the field winding must be go to zero. Fig. 1 shows the amplitudes of the superimposed alternating current of the field winding for an asymmetric load of $25 \%$. From Fig. 1 can be derived two effects. First, the superimposed alternating current which is induced by the magnetic field components with a relative speed to the rotor, increases by an absent damper winding. Second, as we can learn from (5) and (6), the damping factors of all harmonics are different. In other words, the harmonic distortion factor of the field winding current will be reduced by the shielding effect of a complete damper cage. This fact is presented in Fig. 2.

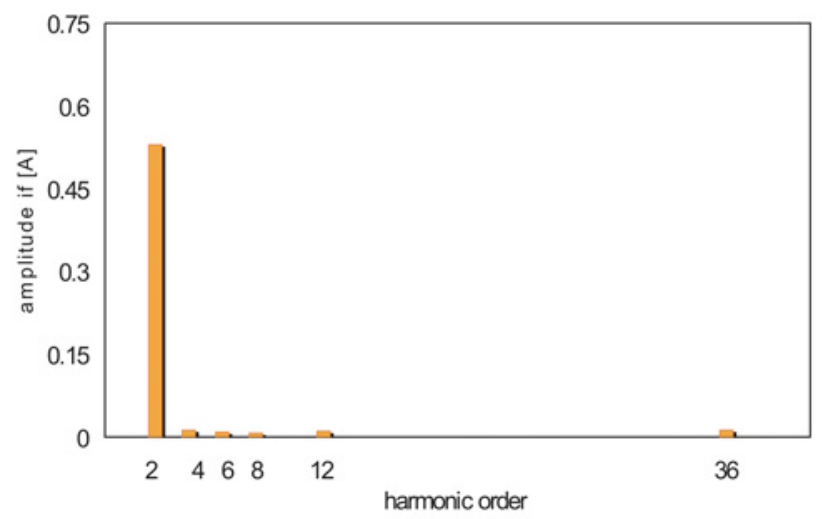

Fig. 2. Fourier analysed field winding current of the test machine with a complete damper cage

The higher harmonic orders in Fig. 2 can be derived from the equations in chapter 2. The main frequency in the field current of an asymmetrical loaded synchronous machine is the double fundamental frequency of the power supply. This means that a part of the backwards rotating field must be compensated by the field winding. But the field winding can only compensate an alternating field. So, a positive and negative rotating field are produced. The negative rotating field produces in the stator a current with a triple fundamental frequency. This frequency produces in the field winding a current with a fourth fundamental order. So the order numbers 2, 4, 6 and 8 can be explained.

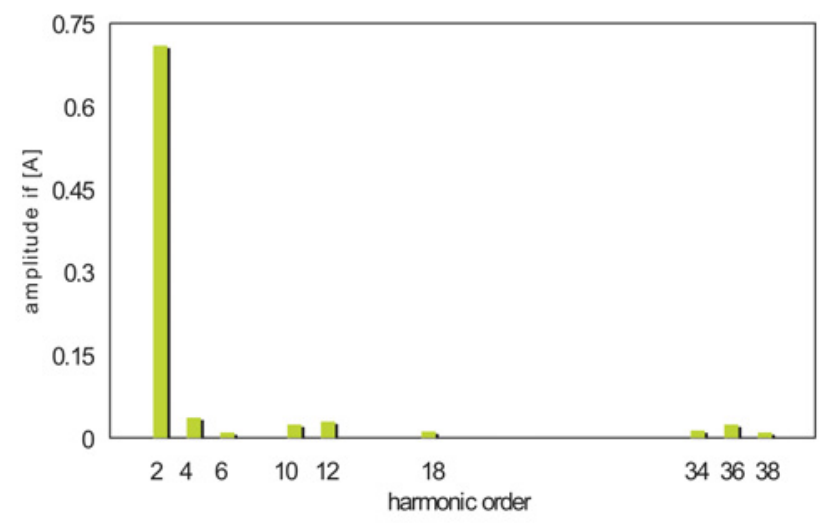

Fig. 3. Fourier analysed field winding current of the test machine without a complete damper cage

The harmonic orders produced by the stator slots are 17 and 19. Compared with (10) it can be said, that the har- monic waves caused by the stator slots produce in the field winding only frequencies from the double fundamental frequency. This is because the relative speed of the harmonic order 19 to the rotor is nearly the wave velocity of the negative rotating field. This fact is given in (16). As expected the stator slot harmonic orders don't appear in the field winding of the machine.

$$
\begin{aligned}
v_{19}^{\prime} & =v_{v}-v_{\text {synchron }}= \\
& =\frac{1}{19} \cdot v_{\text {synchron }}-v_{\text {synchron }}= \\
& =-\frac{18}{19} \cdot v_{\text {synchron }}
\end{aligned}
$$

The influence of the rotor slots are different to the stator slots, because of the waves velocity of the produced higher harmonic waves. The harmonic orders of the waves produced by the rotor slots are 11 and 13 . The waves are given in (17).

$$
\begin{aligned}
& B_{11}=\widehat{B}_{11} \cdot \sin \left(11 \cdot \omega \cdot t+11 \cdot \theta_{S}\right) \\
& B_{13}=\widehat{B}_{13} \cdot \sin \left(13 \cdot \omega \cdot t-13 \cdot \theta_{S}\right)
\end{aligned}
$$

Equation (17) is valid for a synchronous machine because the rotor rotates with the angular frequency $\omega$. Equation (12) is valid in the case of an induction machine. The eleventh flux density wave in equation (13) produces a current in the stator with the eleventh fundamental frequency of the machine. As a result, the produced frequencies in the rotor are 10 and 12. All other rotor harmonic orders can be determined in the same way.

\section{B. Measurement at a machine with a complete damper cage and with an incomplete damper cage.}

When damper bars are broken or when damper bars are missing a complete damper cage will be changed into an incomplete damper cage. The missing damper bars lead to a distorted air gap field, because the missing damper cause an interference field. The idealised interference field of the broken damper bar 3 is given in Fig. 4 .

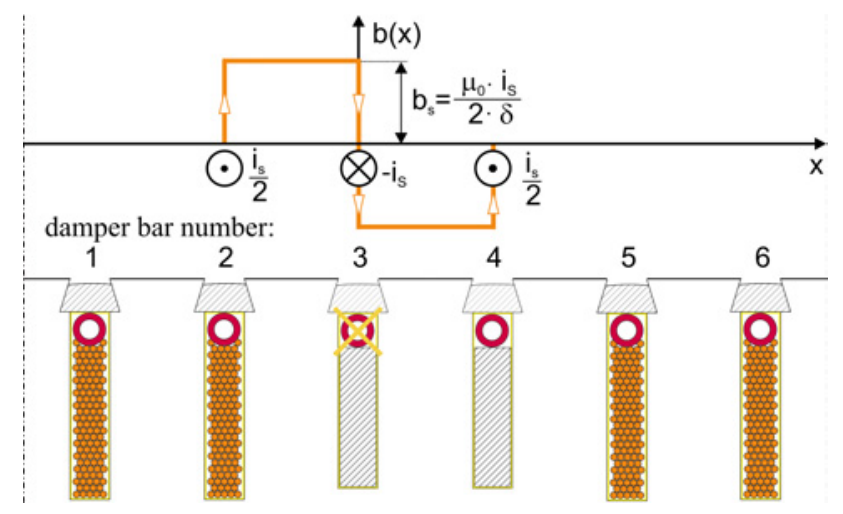

Fig. 4. Idealised interference field distribution

The more damper bars are missing the more the air gap flux density is distorted. Here the chapter must be divided 
into two subsections. First subsection treats with a symmetric incomplete damper cage and the second one deals with an asymmetric incomplete damper cage.

\section{1) Symmetric incomplete built in damper cage}

Normally, a symmetric incomplete damper cage is installed in a salient pole machine. But the test machine has skewed damper bars. So it is possible to model a symmetric incomplete damper cage. Fig. 5 presents the alternating field current produced by the negative sequence rotating field.

From Fig. 5 can be derived two effects. First, the superimposed alternating current which is induced by the magnetic field component with a relative speed to the rotor, increases by a symmetric incomplete damper cage. Furthermore Fig. 5 can be compared with Fig. 1. In other words the effects of a symmetric incomplete built in damper cage are confronted with the effects of a complete built in damper cage. The difference between the complete damper cage and an incomplete asymmetric damper cage is smaller than the difference between a machine without a built in damper.

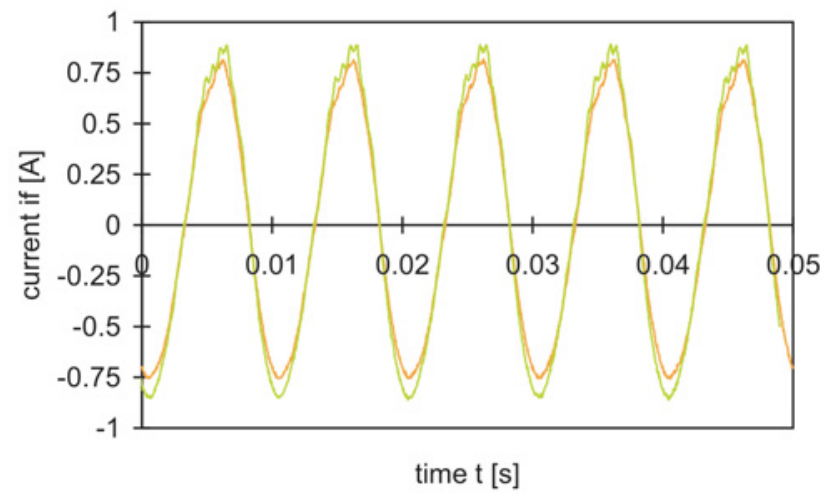

Fig. 5. Field current in the case of one broken damper bar

Second, as we can learn from (5) and (6), the damping factors of all harmonics are different. In other words, the harmonic distortion factor of the field winding current will be reduced by the shielding effect of a complete damper cage. This fact is presented in Fig. 6.

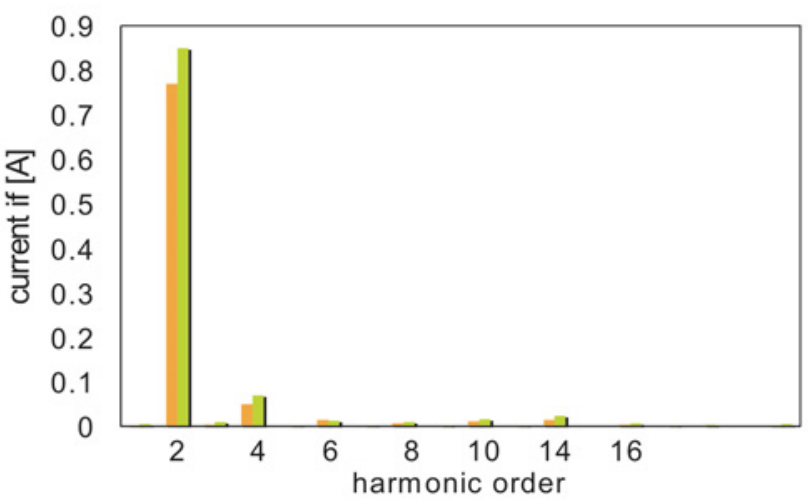

Fig. 6. Fourier analysed field current

\section{2) Asymmetric incomplete built in damper cage}

In the case of one or several broken damper bars the built in complete damper cage is changed into an asymmetric incomplete built in damper cage. First the question about the effects of this asymmetric cage related to the damping effects must be solved. Second the question about the effects of this asymmetric cage related to the dynamic behaviour of the synchronous machine must be solved, too.

It is obvious that the effects of one or two broken damper bars are very small. But it isn't regardless where the spatial positions of the broken damper bars along the circumstance of the rotor are because several broken bars in order increase the interference field. Therefore the effects of a broken damper bar on the induced field winding voltage are determined. For this purpose the synchronous machine is supplied by a symmetrical three phase system and the rotor stands still. Fig. 7 shows the induced voltage into the field winding. It isn't possible to detect the effects of one broken damper in the sum of the pole voltage because the interference field caused by this bar is to small.

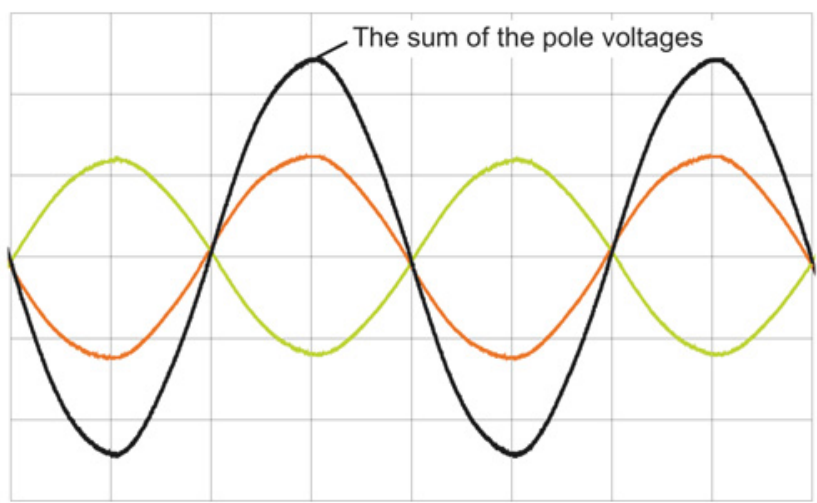

Fig. 7. Sum of the pole voltage in the case of a broken damper bar

Neither the amplitudes of the pole voltages nor their amplitudes of the Fourier analysed pole voltages depend on the effects of one broken damper bar, because the produced interference field is to small.

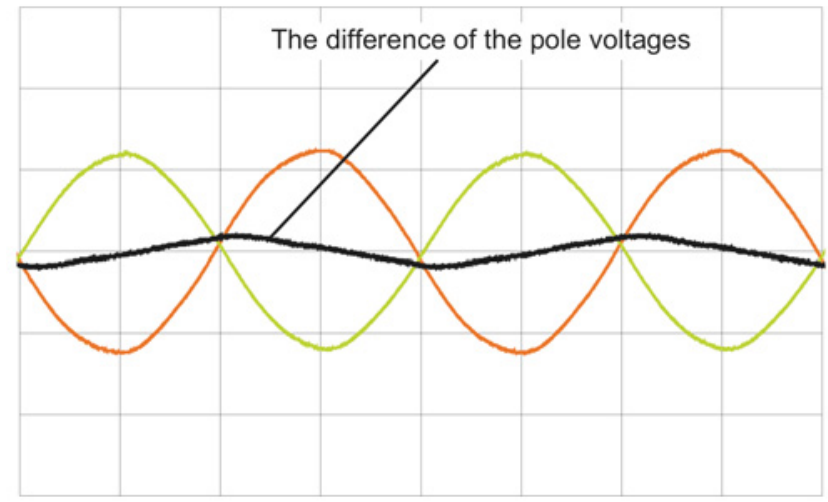

Fig. 8. Difference of the pole voltage in the case of a broken damper bar 
Incidentally, the effects of a broken damper is also to small to change the stationary respectively the dynamic behaviour of a synchronous machine.

For all, the effects of one broken damper can be determined by the measurement of the difference pole pairs voltage such as in Fig. 8. In the case of a symmetrical machine when no damper bar is broken the difference of these voltages must be zero. Now there is an information about a defect damper bar in the amplitude of the difference pole pairs voltages and in its frequency spectrum.

The frequency spectrum of the difference pole pair voltages is given in Fig. 9. The two curves in Fig. 9 present on the one hand the error free machine and on the other hand a defect machine. Now the synchronous machine is asymmetric loaded and the machine works in the lock mode.

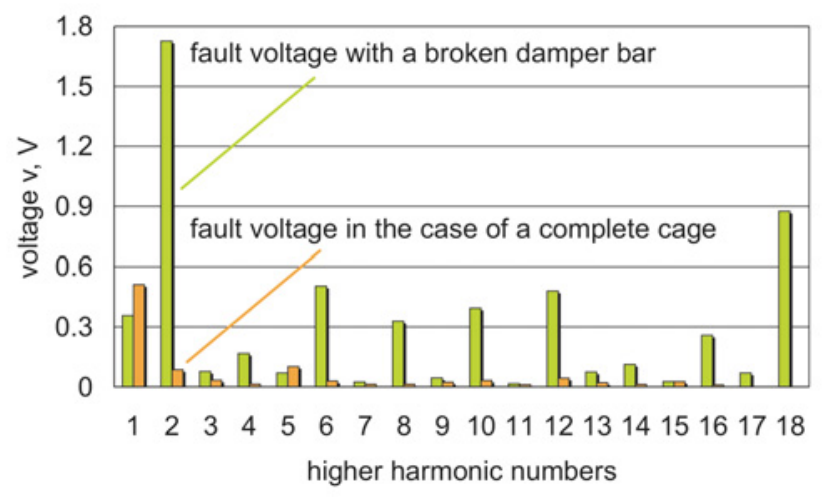

Fig. 9. Frequency spectrum of the error free and the defected synchronous machine

The harmonic orders which can appear in a synchronous machine are determined in chapter 2. Fig. 9 shows the amplitudes of the most interest orders. By this measuring method the spatial fixed damping factor of an asymmetric incomplete built in damper cage can be determined. Principle, the local change of the damping factor caused by a broken damper bar is equal to the change of the damping factor between a machine with a complete damper cage and a machine without an additional built in complete damper cage. But the damping factor of the whole built in damper cage doesn't change by the effects of one broken damper bar, because the produced interference field is averaged along the whole circumstance.

C. Determination of the damping coefficient $C_{D}$ in the case of a machine with a complete damper cage and a machine without an additional built in damper cage.

Normally a synchronous machine has two damper circuits. On the one hand there is the built in damper cage, neither complete or incomplete, and on the other hand there are other massive parts, such as the massive rotor or massive pole shoes, which can mathematical replaced by an additional built in damper cage. It is clear, that an additional damper cage leads to an additional operating behaviour and to additional parameters such as reactances, resistances and time constants.
The damping coefficient $C_{D}$ is a combination of the reactances and time constants of a synchronous machine. In the following the damping coefficients $C_{D}$ of a synchronous machine with one damper circuit and with two almost identical equivalent damper circuits are measured. The test machine is classified to synchronous machines of small power. These machines are characterised by two equivalent damper circuits. This means that the built in damper cage and the additional damper circuit formed of the massive parts and the massive rotor of the machine is of the same value according to its damping effects. This result is obtained by measurements at a small machine without the damping effect of rotor slot wedges. The ratio of the damping coefficients of large machine will be nearly the same, even though the effectiveness of the eddy currents is not as dominant as the effectiveness of the built in damper cage, but this deficit will be balanced by the damping effect of the used rotor slot wedges. The calculated ratio of the damper coefficient $C_{D}$ is given by (18) [2].

$$
a=\frac{C_{D I}}{C_{D I, I I}}=0.57
$$

An absent damper winding leads to a decrease of the damping factor about $43 \%$ compared with a complete built in damper cage.

\section{Conclusion}

The main part of this paper deals with the damping of higher harmonic frequencies in synchronous machines. When the built in damper cage is complete the damping factor respectively the leakage coefficient of the damping cage can be determined by the given equations. But when the built in damper cage turns to an incomplete asymmetric damper cage because of broken damper bars then there are two damping factors.

First, the damping factor of the whole cage. This means that the imperfection of the defect damper cage is averaged along the whole circumstance of the rotor. As a result, the interference field produced by one broken damper is to small to detect it in the voltage of the field winding. When it is to small to distort the voltage of the field winding, it is in any case to small to distort the field winding current.

Second, the damping factor of the defected part of the cage. This means that only the effects of the produced interference field are checked. For that purpose the normal serial connected field winding must be divided into two parts. As a result the difference of the pole pair voltages can be measured.

By a machine without an asymmetry this voltage is zero. In the case of a broken damper bar the damper cage will be asymmetric and the induced difference voltage can be analysed. The result is similar to the result of a machine with a complete damper cage and a machine without an additional damper cage. This means that all harmonic order which are described in chapter 2 are presented in the frequency spectrum of a defected damper cage. 


\section{References}

[1] J. Bacher, "The Effects of an Absent Damper winding in a Turbo Generator on its Operational Behaviour", $8^{\text {th }}$ Portuguese-Spanish Congress on Electrical Engineering (8 CLEEE), Vol. 6, pp. 115120, 2003.

[2] K. Bonfert, Betriebsverhalten der Synchronmaschine, Bedeutung der Kenngrößen für Planung und Betrieb elektrischer Anlagen und Antriebe, Springer, Berlin, Göttingen, Heidelberg (1962), pp. 125-127.
[3] H. Seinsch, Oberfelderscheinungen in Drehfeldmaschinen, Grundlagen zur analytischen und numerischen Berechnung, B. G. Teubner Stuttgart (1992), pp. 40-46.

[4] TJ. Flack , S. Williamson, "Air Gap Field and Pressure Waves in closed-slot Rotor Induction Motors", Electrical Machines and Drives, 1993. Sixth International Conference on (Conf. Publ. No. 376), pp. 552-557, 1993. 